Article

\title{
Effects of Light Quality and Phytochrome Form on Melatonin Biosynthesis in Rice
}

\author{
Ok Jin Hwang ${ }^{1,+}$, Kiyoon Kang ${ }^{2,+}+\mathbb{D}$ and Kyoungwhan Back ${ }^{1, *}$ \\ 1 Department of Biotechnology, College of Agricultural and Life Sciences, Chonnam National University, \\ Gwangju 61186, Korea; smilax@jnu.ac.kr \\ 2 Division of Life Sciences, College of Life Sciences and Bioengineering, Incheon National University, \\ Incheon 22012, Korea; kykang@inu.ac.kr \\ * Correspondence: kback@chonnam.ac.kr; Tel.: +82-62-530-2165 \\ + These authors contributed equally to this work.
}

Received: 17 March 2020; Accepted: 29 March 2020; Published: 30 March 2020

\begin{abstract}
Light is an important factor influencing melatonin synthesis in response to cadmium treatment in rice. However, the effects of light quality on, and the involvement of phytochrome light receptors in, melatonin production have not been explored. In this study, we used light-emitting diodes (LEDs) to investigate the effect of light wavelength on melatonin synthesis, and the role of phytochromes in light-dependent melatonin induction in rice. Upon cadmium treatment, peak melatonin production was observed under combined red and blue $(R+B)$ light, followed by red (R) and blue light (B). However, both far-red (FR) LED light and dark treatment (D) failed to induce melatonin production. Similarly, rice seedlings grown under the $R+B$ treatment showed the highest melatonin synthesis, followed by those grown under $B$ and $R$. These findings were consistent with the results of our cadmium treatment experiment. To further confirm the effects of light quality on melatonin synthesis, we employed rice photoreceptor mutants lacking functional phytochrome genes. Melatonin induction was most inhibited in the phytochrome A mutant (phyA) followed by the $p h y B$ mutant under $\mathrm{R}+\mathrm{B}$ treatment, whereas $p h y B$ produced the least amount of melatonin under $R$ treatment. These results indicate that PhyB is an $\mathrm{R}$ light receptor. Expression analyses of genes involved in melatonin biosynthesis clearly demonstrated that tryptophan decarboxylase (TDC) played a key role in phytochrome-mediated melatonin induction when rice seedlings were challenged with cadmium.
\end{abstract}

Keywords: cadmium; blue light; light intensity; melatonin; rice phy mutants

\section{Introduction}

Melatonin acts as a potent free radical scavenger and antioxidant in almost all organisms, including animals and plants [1-4]. Melatonin acts as a hormone in plants, and as a signaling molecule in a wide range of biological activities [5]. For example, melatonin treatment enhances plant tolerance against many stresses, including salt [6,7], drought [8,9], viruses [10], pathogens [11,12], waterlogging [13], and senescence [14], among others [15-17]. Melatonin is also involved in plant development processes such as growth [18,19], seed viability [20], flowering [21,22], endoplasmic reticulum (ER) quality control [23,24], secondary metabolite synthesis [25], and others [26]. The pleiotropic effects of melatonin are due to the combined effects of its antioxidant activity and signaling or hormonal activity [5], although its metabolites, such as 2-hydroxymelatonin and cyclic 3-hydroxymelatonin, are also involved in physiological activity such as tiller growth $[27,28]$.

In plants, melatonin biosynthesis involves four enzymatic steps, beginning with the catalyzation of tryptophan decarboxylase (TDC), the first committed-step enzyme, into tryptamine. The second 
enzyme is tryptamine 5-hydroxylase, a P450 enzyme that converts tryptamine into serotonin. The penultimate enzyme is serotonin $N$-acetyltransferase (SNAT), which is responsible for $N$-acetylserotonin (NAS) synthesis. The final enzyme is $\mathrm{N}$-acetylserotonin $\mathrm{O}$-methyltransferase (ASMT), which catalyzes NAS into melatonin [29]. In each step, multiple isogenes participate in precursor synthesis; for this reason, it is difficult to generate melatonin knockout plants. Due to the low catalytic efficiency of the final two enzymes (SNAT and ASMT), plant melatonin levels are extremely low; therefore, precise quantification of melatonin levels remains challenging, even with the use of cutting-edge liquid chromatography-mass spectrometry (LC-MS) analytical tools [14,30]. However, plant melatonin synthesis can be induced in response to various stimuli, including pathogen infection and cadmium treatment $[30,31]$. Among many candidates, cadmium is optimal for eliciting melatonin synthesis in rice [32]; however, it cannot induce melatonin production under dark conditions [33]. Therefore, unlike melatonin synthesis in animals, plant melatonin synthesis is dependent on light [34]. In this study, we investigated the effect of light wavelength dependence on melatonin production in rice with and without cadmium treatment, as well as the involvement of phytochromes in this process.

\section{Materials and Methods}

\subsection{Cadmium Treatment}

Rice (Oryza sativa) seeds were sterilized and grown on half-strength Murashige and Skoog (MS) medium under a $12 \mathrm{~h} \mathrm{light}\left(60 \mu \mathrm{mol} \times \mathrm{m}^{-2} \times \mathrm{s}^{-1}\right) / 12 \mathrm{~h}$ dark photoperiod at $28^{\circ} \mathrm{C} / 24^{\circ} \mathrm{C}$ (day/night) for 7 days. We incubated 20 seedlings for 3 days in a 50-mL conical tube, in water containing $0.5 \mathrm{mM} \mathrm{CdCl}_{2}$ (Sigma-Aldrich, St. Louis, MO, USA) at $28^{\circ} \mathrm{C}$ under different light sources: combined monochromic red and blue $(\mathrm{R}+\mathrm{B})$ light $\left(7: 3\right.$ ratio, $\left.60 \mu \mathrm{mol} \times \mathrm{m}^{-2} \times \mathrm{s}^{-1}\right)$, red $\left(\mathrm{R}, 60 \mu \mathrm{mol} \times \mathrm{m}^{-2} \times \mathrm{s}^{-1}\right)$, blue $\left(\mathrm{B}, 60 \mu \mathrm{mol} \times \mathrm{m}^{-2} \times \mathrm{s}^{-1}\right)$, or far-red light $\left(\mathrm{FR}, 4 \mu \mathrm{mol} \times \mathrm{m}^{-2} \times \mathrm{s}^{-1}\right)$. Leaves and stems were harvested for further analyses. The light was provided via light-emitting diodes (LEDs; STECH LED, Gyeonggi-do, Korea).

\subsection{Semi-Quantitative Reverse Transcription-Polymerase Chain Reaction (RT-PCR) Analysis}

Total RNA was isolated from rice plants using a NucleoSpin RNA Plant Kit (Macherey-Nagel, Düren, Germany). First-strand cDNA was synthesized from $2 \mu \mathrm{g}$ total RNA using MG MMLV reverse transcriptase (MGmed, Seoul, Korea) and an oligo $\mathrm{dT}_{18}$ primer at $42{ }^{\circ} \mathrm{C}$ for $1 \mathrm{~h}$. Semi-quantitative RT-PCR was performed as described previously [33].

\subsection{Quantification of Serotonin, N-Acetylserotonin, and Melatonin}

For serotonin and NAS measurements, $0.1 \mathrm{~g}$ frozen samples were pulverized into powder in liquid nitrogen using the TissueLyser II system (Qiagen, Tokyo, Japan) and extracted with $1 \mathrm{~mL}$ methanol for $1 \mathrm{~h}$ at room temperature. Samples were then centrifuged for $10 \mathrm{~min}$ at 12,000 $\times g$, and each supernatant $(20 \mu \mathrm{L})$ was subjected to high-performance liquid chromatography (HPLC) using a fluorescence detection system (Waters, Milford, MA, USA). For melatonin measurements, $0.1 \mathrm{~g}$ samples were pulverized into powder in liquid nitrogen and extracted with $1 \mathrm{~mL}$ chloroform for $16 \mathrm{~h}$ at $4{ }^{\circ} \mathrm{C}$. Chloroform extracts $(200 \mu \mathrm{L})$ were completely evaporated and dissolved in $0.1 \mathrm{~mL} \mathrm{40 \%} \mathrm{methanol;}$ $20 \mu \mathrm{L}$ aliquots were injected into the HPLC system, which included a fluorescence detector (Waters). All measurements were performed in triplicate.

\subsection{Statistical Analysis}

Means were compared using analysis of variance (ANOVA) with IBM SPSS Statistics software (IBM, Armonk, NY, USA, version 25.0), followed by post-hoc Tukey's honest significant difference (HSD) tests. A $P$-value $<0.05$ was taken to indicate statistical significance. All data are presented as means \pm standard deviation. 


\section{Results}

\section{1. $R+B$ Treatment Induced Peak Melatonin Synthesis upon Cadmium Treatment}

To determine the light wavelength most effective for inducing melatonin production, 7-day-old rice seedlings were challenged with cadmium for 3 days under four different LED wavelengths. As shown in Figure 1, melatonin production was not induced in response to cadmium under the dark treatment (D). Light-triggered melatonin production was highest under the $\mathrm{R}+\mathrm{B}$ treatment, followed by the R and B treatments (Figure 1D). FR produced melatonin levels comparable to those of the $\mathrm{D}$ treatment. Similar to melatonin, its precursors serotonin and NAS were also maximally induced by $R+B$, followed by $R$ and $B$, whereas no induction was observed under the $D$ or FR treatments (Figure 1B,C). These data strongly suggest that melatonin induction upon cadmium treatment is completely dependent on specific light wavelengths. Maximum melatonin production under $\mathrm{R}+\mathrm{B}$ treatment appears to be closely associated with the spectrum of photosynthetically active radiation, since $R+B$ produces a higher photosynthetic rate than the sum of $R$ and B alone [35].
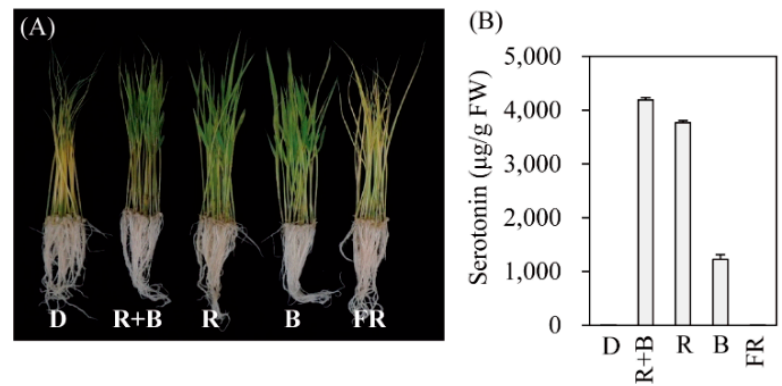

(C)

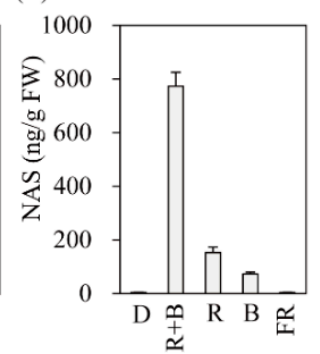

(D)

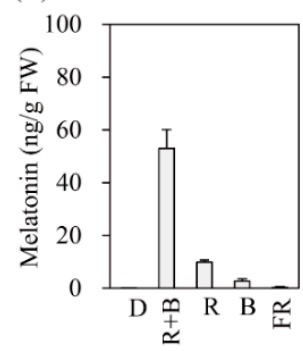

Figure 1. Effects of various light wavelengths on serotonin, $N$-acetylserotonin, and melatonin production in rice seedlings. (A) Phenotypes, (B) serotonin, (C) $N$-acetylserotonin, and (D) melatonin levels in response to cadmium treatment under various light conditions. Seven-day-old rice seedlings were rhizosperically challenged with $0.5 \mathrm{mM} \mathrm{CdCl}_{2}$ for 3 days under continuous light wavelength condition. D, dark; R + B, combined red and blue LED light (7:3 ratio); R, red LED light; B, blue LED light; FR, far-red LED light. Light intensity in $\mathrm{R}+\mathrm{B}, \mathrm{R}$, and $\mathrm{B}$ was equal to $60 \mu \mathrm{mol} \times \mathrm{m}^{-2} \times \mathrm{s}^{-1}$ whereas FR was $4 \mu \mathrm{mol} \times \mathrm{m}^{-2} \times \mathrm{s}^{-1}$. Values are means \pm standard deviations of three independent experiments. FW, fresh weight.

\subsection{Melatonin Levels in Rice Seedlings Grown under Various Light Conditions}

To determine whether melatonin production is dependent on light wavelength even in the absence of elicitors such as cadmium, rice seeds were germinated in MS medium and grown under various light conditions. As shown in Figure 2, rice seedlings grown under the D treatment produced about $0.3 \mathrm{ng} / \mathrm{g}$ fresh weight (FW) melatonin, which was identical to that of the FR treatment. In contrast, rice seedlings grown under $\mathrm{R}+\mathrm{B}$ light produced about $1.5 \mathrm{ng} / \mathrm{g}$ FW melatonin, which was 5-fold higher than that of the $\mathrm{D}$ treatment, confirming that melatonin production is light-dependent. The melatonin production of rice seedlings grown under R and B alone was about $1 \mathrm{ng} / \mathrm{g}$ FW. The key gene responsible for light-dependent melatonin induction appears to be TDC (Figure 2B). TDC mRNA expression was induced under all light conditions, including FR, but not under the D treatment. Similarly, SNAT1 and SNAT2 expression increased under all light conditions compared to that of the D treatment. ASMT expression varied significantly among light conditions. The expression level of melatonin 3-hydroxylase $(\mathrm{M} 3 \mathrm{H})$, which catalyzes melatonin into cyclic 3-hydroxymelatonin, remained unchanged, whereas that of melatonin 2-hydroxylase $(\mathrm{M} 2 \mathrm{H})$, which catalyzes melatonin into 2-hydroxymelatonin, was increased under $\mathrm{R}+\mathrm{B}, \mathrm{R}$, and FR light conditions, and decreased under B light conditions. Based on these results, it was difficult to identify the specific genes responsible for melatonin production under various light wavelengths. 
(A)

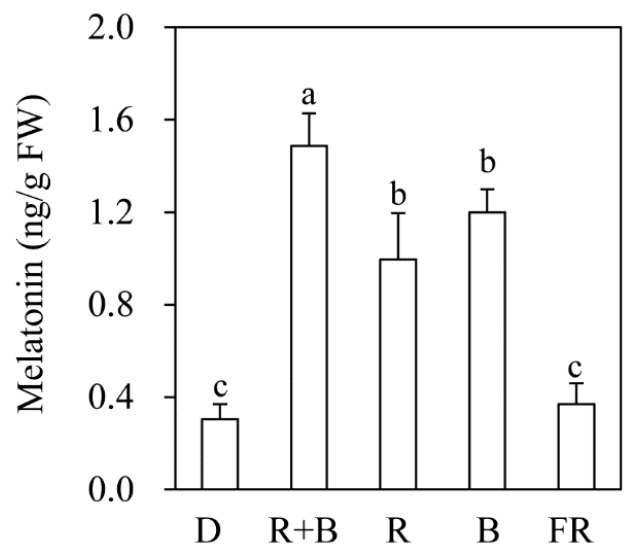

(B)

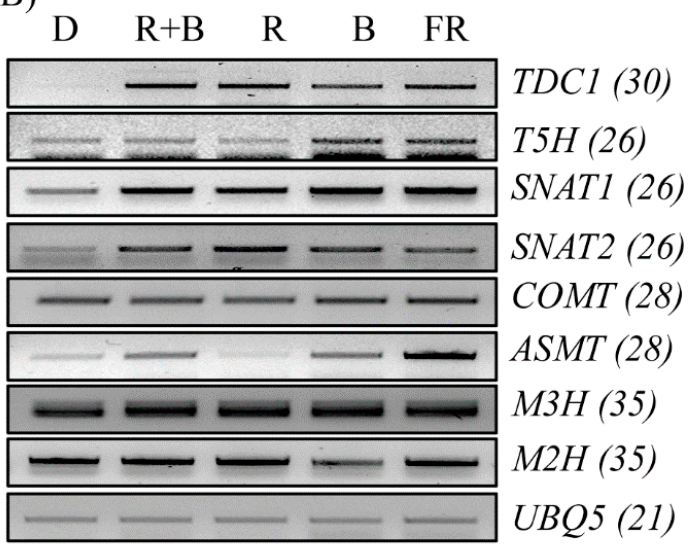

Figure 2. Effects of light wavelength on melatonin synthesis and expression levels of corresponding genes. (A) Effects of light quality on melatonin synthesis. (B) Expression levels of melatonin biosynthetic and catabolic genes. Dehusked rice seeds were germinated and grown in half-strength Murashige and Skoog (MS) medium for 7 days under continuous light conditions as described in Figure 1. TDC1, tryptophan decarboxylase 1; T5H, tryptamine 5-hydroxylase; SNAT, serotonin $N$-acetyltransferase; COMT, caffeic acid O-methyltransferase; ASMT, $\mathrm{N}$-acetylserotonin $\mathrm{O}$-methyltransferase; $\mathrm{M} 3 \mathrm{H}$, melatonin 3-hydroxylase; $M 2 H$, melatonin 2-hydroxylase, $U B Q 5$, ubiquitin 5 . Values are means \pm standard deviations of three independent experiments. FW, fresh weight. Different letters denote significant differences as determined by Tukey's post hoc HSD test at $P<0.05$. Numbers in parentheses are the numbers of polymerase chain reaction (PCR) cycles. GenBank accession numbers are AK069031 (TDC1), AK071599 (T5H), AK059369 (SNAT1), AK068156 (SNAT2), AK064768 (COMT), AK072740 (ASMT1), AK067086 (M3H), AK119413 (M2H), and Os03g13170 (UBQ5).

\subsection{Phytochrome-Dependent Melatonin Production}

Rice contains three types of phytochromes (PhyA, PhyB, and PhyC) that perceive R and FR light [36]. To determine whether light-dependent melatonin production is associated with light receptor phytochrome, we employed rice phytochrome (phy) mutants to see whether these mutants show impaired melatonin production under various light conditions $[37,38]$; these mutants were obtained from the Crop Biotech Institute at Kyung Hee University (Seoul, Korea) [39]. T-DNA insertion sites and phenotypes of 7-day-old seedlings of three phy mutants are shown in Figure 3. Following cadmium challenge under various light conditions, melatonin production was most severely inhibited in the phy $A$ mutant under $\mathrm{R}+\mathrm{B}$ treatment, followed by $p h y B$, whereas melatonin production in the phyC mutant remained similar to that of the wild-type (WT) (Figure 4A). Under R treatment, melatonin production was most reduced in the phyB mutant, followed by the phy $A$ mutant, suggesting that PhyB is the major $\mathrm{R}$ light receptor. Similar to the $\mathrm{R}+\mathrm{B}$ condition, the phy $\mathrm{C}$ mutant produced comparable amounts of melatonin to WT under the $\mathrm{R}$ condition. In response to the $\mathrm{B}$ treatment, melatonin synthesis was significantly diminished only in the phy $A$ mutant, whereas phyB and phyC showed no difference in melatonin synthesis compared to WT. Thus, PhyA predominantly receives B light. The role of PhyC appears to be negligible in terms of light perception and melatonin production in response to cadmium treatment. Notably, melatonin levels were much higher under $\mathrm{R}+\mathrm{B}$ treatment compared to the sum of the $\mathrm{R}$ and $\mathrm{B}$ treatments alone.

To identify a key regulatory gene among the phy mutants responsible for melatonin production, we monitored the expression of melatonin biosynthetic and catabolic genes under $\mathrm{R}+\mathrm{B}$ treatment. The severe reduction in melatonin production observed in the phyA mutant was closely associated with lower expression levels of TDC and caffeic acid O-methyltransferase (COMT) (Figure 4B), which are key genes for light-dependent melatonin synthesis in response to cadmium treatment [33]. 
(A)

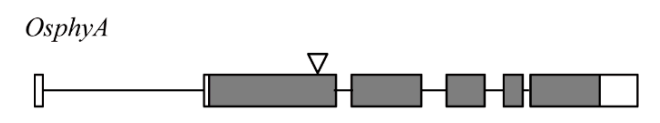

$O s p h y B$

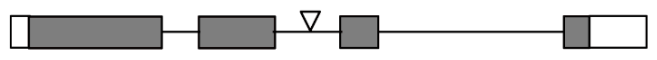

OsphyC

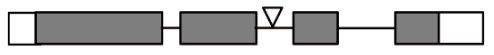

(B)

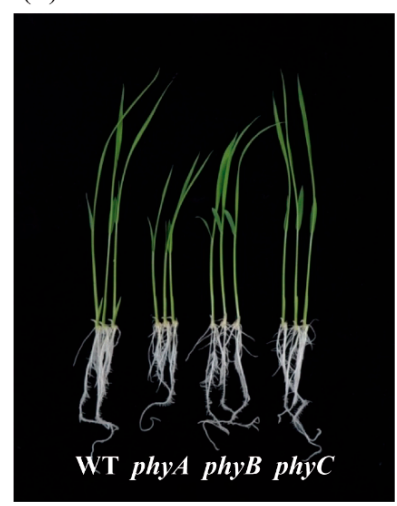

Figure 3. T-DNA insertional lines of rice Phy genes and their seedling phenotypes. (A) Simple schematic diagrams of rice Phy gene structures and T-DNA insertion sites [37]. (B) Phenotypes of 7-day-old rice seedlings grown in half-strength MS medium under a $12 \mathrm{~h}$ light $/ 12 \mathrm{~h}$ dark cycle at $28^{\circ} \mathrm{C}$. Exons (filled boxes), introns (lines), and 5' - and $3^{\prime}$-untranslated regions (open boxes) are shown. Reverse triangles indicate T-DNA insertion sites.
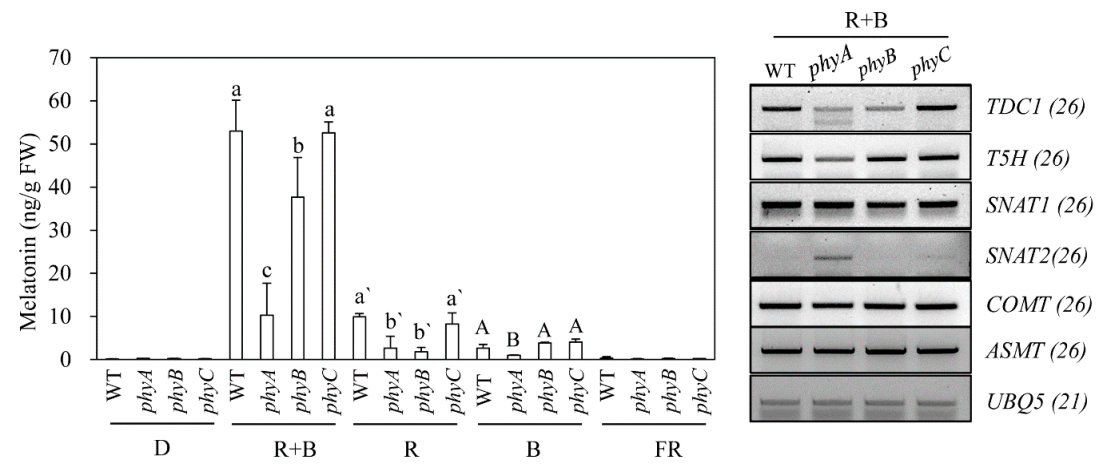

Figure 4. Effects of various light wavelengths on melatonin synthesis in phy mutants. (A) Melatonin levels in response to cadmium treatment under various light conditions in phy mutants. (B) Expression levels of melatonin biosynthetic genes. Seven-day-old rice seedlings were rhizosperically challenged with $0.5 \mathrm{mM} \mathrm{CdCl}_{2}$ for 3 days under various light wavelength condition as described in Figure 1. Values are means \pm standard deviations of three independent experiments. FW, fresh weight. Different letters denote significant differences as determined by Tukey's post hoc HSD test at $P<0.05$. GenBank numbers are presented in Figure 2.

\subsection{Effects of Light Intensity on Serotonin and Melatonin Production under $R+B$ Treatment}

Serotonin is the only essential precursor for melatonin biosynthesis in plants [29]. In plants, the synthesis of both serotonin and melatonin is dependent on light (Figure 1) [40]. To determine whether light intensity affected the levels of serotonin, NAS, and melatonin in the phy mutants under R + B treatment, we measured these compounds in $\mathrm{R}+\mathrm{B}$ treatments with two different light intensity values: 30 and $60 \mu \mathrm{mol} \times \mathrm{m}^{-2} \times \mathrm{s}^{-1}$. Serotonin levels were indistinguishable between the light intensity treatments among WT and the $p h y B$ and phyC mutants; however, the phyA mutant had lower serotonin levels (Figure 5A). In contrast, NAS production increased as light intensity increased in WT and the phy C mutant, whereas no difference was observed in the $p h y A$ or phyB mutant, suggesting that these mutants failed to perceive light intensity differences (Figure 5B). As observed for melatonin, the WT and phy $C$ mutant responded to increased light intensity by enhancing melatonin production (Figure 5C). However, phy $A$ completely lost its ability to increase melatonin production as light intensity increased. Although phyB responded to light intensity, its responsiveness was lower than that of WT and the phyC mutant. These results indicate that phyA cannot perceive light as well as light intensity, resulting in a severe decrease in melatonin production in response to cadmium treatment under the $\mathrm{R}+\mathrm{B}$ condition. 

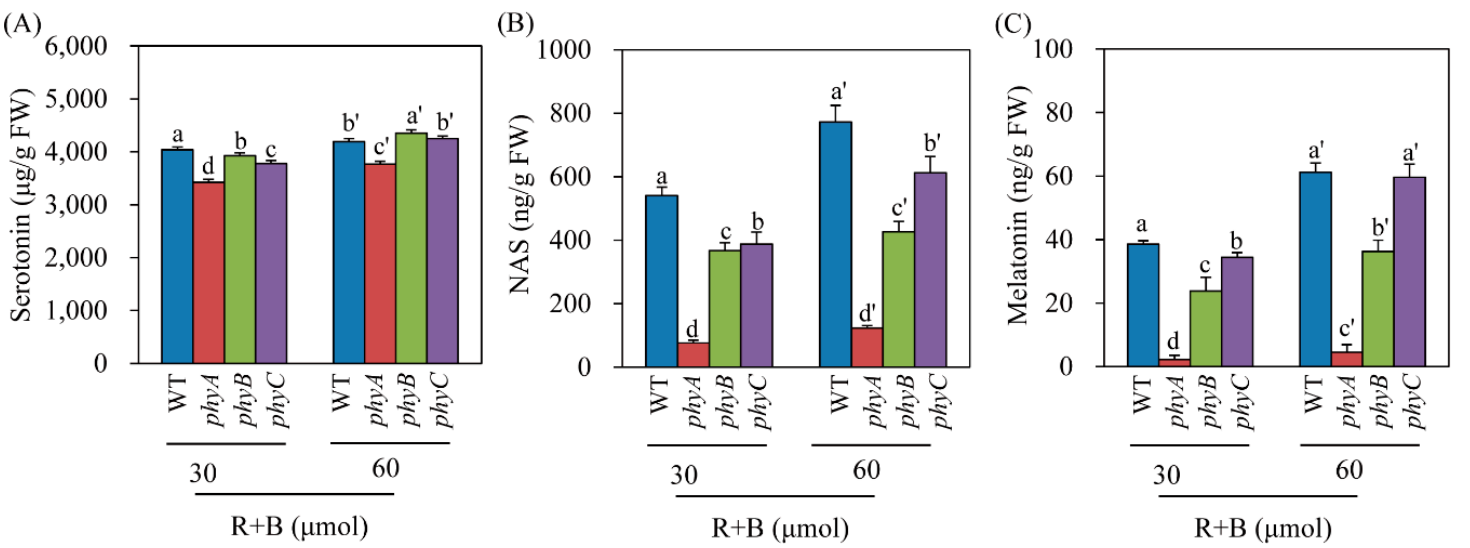

Figure 5. Effects of light intensity on (A) serotonin, (B) $N$-acetylserotonin, and (C) melatonin levels in phy mutants in response to cadmium treatment under two light intensity conditions. Seven-day-old rice seedlings were rhizosperically challenged with $0.5 \mathrm{mM} \mathrm{CdCl}_{2}$ for 3 days under two different continuous light intensity conditions. Light intensity $(\mathrm{R}+\mathrm{B})$ was either 30 or $60 \mu \mathrm{mol} \times \mathrm{m}^{-2} \times \mathrm{s}^{-1}$. Values are means \pm standard deviations of three independent experiments. FW, fresh weight. Different letters denote significant differences as determined by Tukey's post hoc HSD test at $P<0.05$.

\subsection{Seed Melatonin Levels in Healthy phy Mutants}

Melatonin production in response to cadmium treatment may not accurately reflect in vivo plant melatonin levels. Thus, to confirm our findings, we quantified melatonin levels in rice seeds, which have a slightly higher melatonin content than other tissues such as green leaves; seeds also contain far fewer compounds that interfere with the HPLC chromatogram than green leaves. WT rice seeds contained $0.4 \mathrm{ng} / \mathrm{g}$ FW melatonin, which was significantly more than that of the phy mutant (Figure 6). For example, phy $A$ and phyC contained $0.12 \mathrm{ng} / \mathrm{g}$ FW melatonin and phyB contained $0.3 \mathrm{ng} / \mathrm{g}$ FW melatonin. These in vivo data were slightly different from our cadmium treatment data. In response to cadmium treatment, the phyC mutant and WT induced melatonin synthesis to a similar extent; in seeds, melatonin levels decreased to a similar extent in the phyA and phyC mutants. Conversely, phyB produced less melatonin than WT under cadmium treatment, and in seeds. Although different melatonin responses were observed between control seeds and cadmium-treated seedlings among the three phy mutants, our results clearly demonstrate that melatonin synthesis is dependent on light, as well as phytochrome light receptors.

(A)

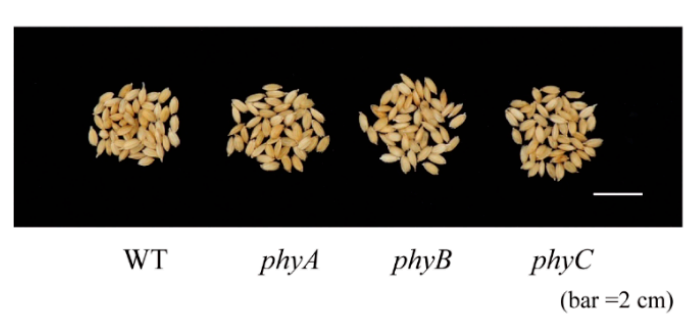

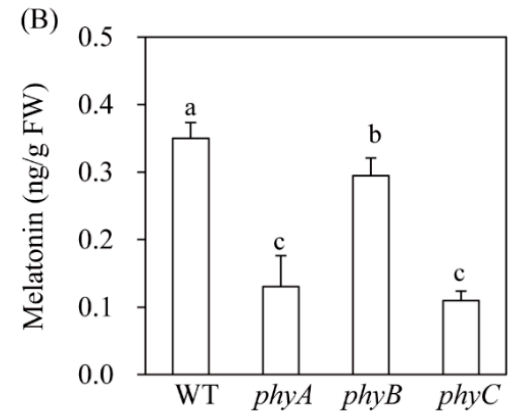

Figure 6. Seed melatonin levels in phy mutants. (A) Water-imbibed rice seeds after $9 \mathrm{~h}$. (B) Melatonin levels in phy mutants. WT, wild type; FW, fresh weight. Different letters indicate significant differences, as determined by Tukey's honest significant difference (HSD) post-hoc test at a level of $P<0.05$. 


\section{Discussion}

\subsection{Biological Significance of the Dependency of Plant Melatonin Synthesis on Light}

Unlike melatonin in animals, plant melatonin levels are higher under high-light versus low-light conditions [41]. Melatonin levels in Glycyrrhiza uralensis roots were first discovered to be higher under $\mathrm{R}$ light than under $\mathrm{B}$ or white light, indicating that light wavelength may influence plant melatonin levels [42]. The production of melatonin and its metabolite $\mathrm{N}^{1}$-acetyl- $\mathrm{N}^{2}$-formyl-5-methoxykynuramine (AFMK) has shown a rhythmic pattern, peaking during the late light phase in water hyacinth [43]. These findings indicate that light intensity and light wavelength are pivotal factors in plant melatonin production. This hypothesis was confirmed by Lee et al. [33], who reported that melatonin induction required light when rice seedlings were challenged with cadmium; their detailed mechanistic study demonstrated that cadmium treatment promoted an oxidative burst, characterized by increased $\mathrm{H}_{2} \mathrm{O}_{2}$ and NO production, which triggered melatonin synthesis. Due to the close relationship between the oxidative burst and melatonin induction, it is highly likely that plant melatonin is involved in regulating the cellular reactive oxygen species (ROS) balance in both normal healthy cells and stressed cells [16]. Our observation that melatonin synthesis increased under R + B treatment compared to the sum of $\mathrm{R}$ and $\mathrm{B}$ alone strongly implies an intimate relationship between melatonin and photosynthesis, because photosynthesis shows far greater enhancement under $\mathrm{R}+\mathrm{B}$ treatment relative to the sum of the $\mathrm{R}$ and $\mathrm{B}$ treatments alone [34]. Under light conditions, chloroplasts are a major catalyst of ROS production due to partial reduction of $\mathrm{O}_{2}$ in plants. Light-harvesting complexes, such as photosystem I and II (PSI and PSII, respectively) and the electron transport chain (ETC), can generate a range of ROS including superoxide $\left(\mathrm{O}_{2}^{-}\right)$, hydrogen peroxide $\left(\mathrm{H}_{2} \mathrm{O}_{2}\right)$, and singlet oxygen $\left({ }^{1} \mathrm{O}_{2}\right)$, which is generated from chloroplasts and triggers membrane lipid peroxidation, leading to growth inhibition and even cell death by damaging the PSII reaction center [44]. In response to abiotic stresses, such as drought and high light conditions, chloroplasts produce more ROS, such that more ROS scavengers are required, including antioxidants and antioxidant enzymes [44]. The close relationship between high photosynthesis activity and peak melatonin synthesis under the $\mathrm{R}+\mathrm{B}$ condition has a genetic basis; the Arabidopsis melatonin-deficient snat1 knockout mutant showed enhanced susceptibility to high light stress [45]. In addition, chloroplasts are major sites for melatonin biosynthesis, and contain the penultimate SNAT enzyme and key regulatory enzymes, such as $\mathrm{M} 2 \mathrm{H}$ and $\mathrm{N}$-acetylserotonin deacetylase [46-48]. Thus, melatonin plays an important role in maintaining chloroplast integrity by upregulating melatonin synthesis during photosynthesis, or in response to abiotic stresses, to efficiently scavenge ROS and induce ROS-scavenging enzymes [5].

\subsection{Photoreceptor-Mediated Melatonin Production in Plants}

Plants perceive light signals through a number of photoreceptors including phytochromes, cryptochromes, phototropins, and UVR8. Phytochromes absorb the R/FR region of the light spectrum (600-750 nm), whereas cryptochromes and phototropins absorb B/ultraviolet light (280-500 nm). UVR8 is involved in sensing ultraviolet light in the $280-315 \mathrm{~nm}$ range, and is highly involved in plant stress responses [49]. Based on melatonin synthesis induction via light and ROS in plants [33], it is clear that all three photoreceptors are necessary for plant melatonin synthesis. Among the three photoreceptors, phytochromes have been extensively studied due to their involvement in a vast array of plant biological functions, including germination, de-etiolation, the shade-avoidance response, photosynthesis, photomorphogenesis, and senescence [50]. Phytochromes exist in two interconvertible forms, namely inactive Pr and active Pfr; R light induces inactive Pr to become active Pfr, whereas FR light transforms active Pfr into inactive Pf. Active Pfr is translocated into the nucleus, where it mediates various transcriptional activities. Rice contains three types of phytochromes (PhyA, PhyB, and PhyC); PhyA and PhyB perceive R light in a redundant manner, whereas PhyA is involved in perceiving FR light [51]. In the context of phytochrome functions and melatonin synthesis, we predicted that the $\mathrm{R}$ treatment would perform best in terms of inducing melatonin synthesis, if phytochromes were 
exclusively involved in melatonin induction in response to cadmium treatment. However, $\mathrm{R}+\mathrm{B}$ treatment, rather than $\mathrm{R}$, yielded the highest melatonin production, at $50 \mathrm{ng} / \mathrm{g} \mathrm{FW}$, which was 5-fold higher than that of the $\mathrm{R}$ treatment (Figure 1D). Consistent with this result, melatonin induction was most significantly inhibited under $\mathrm{R}+\mathrm{B}$ treatment in the phy $A$ mutant, followed by $p h y B$ rather than phyC. In response to $\mathrm{B}$ treatment, the $p h y A$ mutant failed to induce melatonin synthesis, whereas melatonin synthesis was not reduced in the $p h y B$ and phyC mutants. This result suggests that, in the context of melatonin synthesis in rice, PhyA can perceive B light. Thus, phytochromes are required for melatonin synthesis, by absorbing light for photosynthesis and thus inducing the generation of a series of ROS, which are key signaling molecules for melatonin synthesis induction in response to cadmium treatment. The active Pfr and inactive Pr interconvertible phytochrome forms are not directly responsible for melatonin synthesis; rather, phytochromes are indirectly involved in this process through light absorption. The most important wavelengths for photosynthesis are R (600-700 nm) and B light (420-450 nm), which coincide well with chlorophyll absorption peaks. Collectively, the wavelengths for maximum melatonin synthesis are in exact agreement with those for maximum photosynthesis, suggesting that melatonin acts as a master regulator, enhancing photosynthesis by scavenging ROS generated within chloroplasts [5]. This conclusion is consistent with the findings of many previous studies, which reported that melatonin deficiency leads to growth inhibition [52,53] and premature senescence [14].

\section{Conclusions}

Unlike animals, plants require light for melatonin synthesis. However, no studies have clarified the roles of light quality and photoreceptors in plant melatonin biosynthesis. In this study, we investigated the optimum wavelengths for melatonin synthesis in rice, as well as the role of phytochromes in this process. We treated rice seedlings with cadmium to induce melatonin synthesis under light at various wave lengths and found that $R+B$ treatment enhanced melatonin production to a greater extent than the sum of the $\mathrm{R}$ and $\mathrm{B}$ treatments alone. This is the first study to report that phytochromes are involved in melatonin production by absorbing $\mathrm{R}+\mathrm{B}$ light, rather than in a Pf/Pfr light-dependent manner. The maximum melatonin production under $\mathrm{R}+\mathrm{B}$ treatment was similar to the optimum photosynthesis rate under $\mathrm{R}+\mathrm{B}$ treatment, suggesting that melatonin is functionally coupled with photosynthesis, possibly due to its potent antioxidant activity and role in inducing antioxidant enzymes.

Author Contributions: Conceptualization, K.B.; data curation, O.J.H., and K.K.; formal analysis, O.J.H., and K.K.; funding, K.B.; writing-original draft, K.B.; and writing-review and editing, K.B. All authors have read and agreed to the published version of the manuscript.

Funding: This research was supported by grants from the Next-Generation BioGreen 21 Program (SSAC Project No. PJ01325501) and the Basic Science Research Program of the National Research Foundation of Korea (2017R1A2A2A05069253) funded by the Ministry of Education, Republic of Korea.

Conflicts of Interest: The authors declared no conflicts of interest.

\section{References}

1. Zhao, D.; Yu, Y.; Shen, Y.; Liu, Q.; Zhao, Z.; Sharma, R.; Reiter, R.J. Melatonin synthesis and function: Evolutionary history in animals and plants. Front. Endocrinol. 2019, 10, 249. [CrossRef]

2. Pal, P.K.; Bhattacharjee, B.; Chattopadhyay, A.; Bandyopadhyay, D. Pleiotropic roles of melatonin against oxidative stress mediated tissue injury in the gastrointestinal tract: An overview. Melatonin Res. 2019, 2, 158-184. [CrossRef]

3. Hardeland, R. Melatonin in the evolution of plants and other phototrophs. Melatonin Res. 2019, 2, 10-36. [CrossRef]

4. Tan, D.X.; Reiter, R.J. Mitochondria: The birth place, battle ground and site of melatonin metabolism in cells. Melatonin Res. 2019, 2, 44-66. [CrossRef]

5. Arnao, M.B.; Hernández-Ruiz, J. Melatonin: A new plant hormone and/or a plant master regulator. Trends Plant Sci. 2019, 24, 38-48. [CrossRef] 
6. Cen, H.; Wang, T.; Liu, H.; Tian, D.; Zhang, Y. Melatonin application improves salt tolerance of alfalfa (Medicago sativa L.) by enhancing antioxidant capacity. Plants 2020, 9, 220. [CrossRef]

7. Zhao, G.; Yu, X.; Lou, W.; Wei, S.; Wang, R.; Wan, Q.; Shen, W. Transgenic Arabidopsis overexpressing MsSNAT enhances salt tolerance via the increase in autophagy, and the reestablishment of redox and ion homeostasis. Environ. Exp. Bot. 2019, 164, 20-28. [CrossRef]

8. Huang, B.; Chen, Y.-E.; Zhao, Y.-Q.; Ding, C.-B.; Liao, J.-Q.; Hu, C.; Zhou, L.-J.; Zhang, Z.-W.; Yuan, S.; Yuan, M. Exogenous melatonin alleviates oxidative damages and protects photosystem II in maize seedlings under drought stress. Front. Plant Sci. 2019, 10, 677. [CrossRef]

9. Yang, W.J.; Du, Y.T.; Zhou, Y.B.; Chen, J.; Xu, Z.S.; Ma, Y.Z.; Chen, M.; Min, D.H. Overexpression of TaCOMT improves melatonin production and enhances drought tolerance in transgenic Arabidopsis. Int. J. Mol. Sci. 2019, 20, 652. [CrossRef]

10. Zhao, L.; Chen, L.; Gu, P.; Zhan, X.; Zhang, Y.; Hou, C.; Wu, Z.; Wu, Y.F.; Wang, Q.C. Exogenous application of melatonin improves plant resistance to virus infection. Plant Pathol. 2019, 68, 1287-1295. [CrossRef]

11. Li, C.; He, Q.; Zhang, F.; Yu, J.; Li, C.; Zhao, T.; Zhang, Y.; Xie, Q.; Su, B.; Mei, L.; et al. Melatonin enhances cotton immunity to Verticillium wilt via manipulating lignin and gossypol biosynthesis. Plant J. 2019, 100, 784-800. [CrossRef]

12. Yu, Y.; Bian, L.; Jiao, Z.; Keke, Y.; Wan, Y. Molecular cloning and characterization of a grapevine (Vitis vinifera L.) serotonin $N$-acetyltransferase (VvSNAT2) gene involved in plant defense. BMC Genomics 2019, 20, 880. [CrossRef]

13. Zhang, Q.; Liu, X.; Zhang, Z.; Liu, N.; Li, D.; Hu, L. Melatonin improved waterlogging tolerance in alfalfa (Medicago sativa) by reprogramming polyamine and ethylene metabolism. Front. Plant Sci. 2019, 10, 44. [CrossRef]

14. Hong, Y.; Zhang, Y.; Sinumporn, S.; Yu, N.; Zhan, X.; Shen, X.; Chen, D.; Yu, P.; Wu, W.; Liu, Q.; et al. Premature leaf senescence 3 , encoding a methyltransferase, is required for melatonin biosynthesis in rice. Plant J. 2018, 95, 877-891. [CrossRef]

15. Arnao, M.B.; Hernández-Ruiz, J. Melatonin as a chemical substance or as phytomelatonin rich-extracts for use as plant protector and/or biostimulant in accordance with EC legislation. Agronomy 2019, 9, 570. [CrossRef]

16. Arnao, M.B.; Hernández-Ruiz, J. Melatonin and reactive oxygen and nitrogen species: A model for the plant redox network. Melatonin Res. 2019, 2, 152-168. [CrossRef]

17. Moustafa-Farag, M.; Almoneafy, A.; Mahmoud, A.; Elkelish, A.; Arnao, M.B.; Li, L.; Ai, S. Melatonin and its protective role against biotic stress impacts on plants. Biomolecules 2020, 10, 54. [CrossRef]

18. Hwang, O.J.; Back, K. Melatonin is involved in skotomorphogenesis by regulating brassinosteroid biosynthesis in plants. J. Pineal Res. 2018, 65, e12495. [CrossRef]

19. Yang, J.; Zhang, C.; Wang, Z.; Sun, S.; Zhan, R.; Zhao, Y.; Ma, B.; Ma, F.; Li, M. Melatonin-mediated sugar accumulation and growth inhibition in apple plants involves down-regulation of fructokinase 2 expression and activity. Front. Plant Sci. 2019, 10, 150. [CrossRef]

20. Hwang, O.J.; Back, K. Simultaneous suppression of two distinct serotonin $N$-acetyltransferase isogenes by RNA interference leads to severe decreases in melatonin and accelerated seed deterioration in rice. Biomolecules 2020, 10, 141. [CrossRef]

21. Zhang, H.; Wang, L.; Shio, K.; Shan, D.; Zhu, Y.; Wang, W.; Bai, Y.; Yan, T.; Zheng, X.; Kong, J. Apple tree flowering is mediated by low level of melatonin under the regulation of seasonal light signal. J. Pineal Res. 2019, 66, e12551. [CrossRef] [PubMed]

22. Lee, H.Y.; Lee, K.; Back, K. Knockout of Arabidopsis serotonin N-acetyltransferase-2 reduces melatonin levels and delays flowering. Biomolecules 2019, 9, 712. [CrossRef] [PubMed]

23. Lee, H.Y.; Back, K. Melatonin plays a pivotal role in conferring tolerance against endoplasmic reticulum stress via mitogen-activated protein kinases and bZIP60 in Arabidopsis thaliana. Melatonin Res. 2018, 1, $93-107$. [CrossRef]

24. Choi, G.H.; Back, K. Suppression of melatonin 2-hydroxylase increases melatonin production leading to the enhanced abiotic stress tolerance against cadmium, senescence, salt, and tunicamycin in rice plants. Biomolecules 2019, 9, 589. [CrossRef] 
25. Xia, H.; Shen, Y.; Shen, T.; Wang, X.; Zhang, X.; Hu, P.; Liang, D.; Lin, L.; Deng, H.; Wang, J.; et al. Melatonin accumulation in sweet cherry and its influence on fruit quality and antioxidant properties. Molecules 2020, 25, 75. [CrossRef]

26. Xu, T.; Chen, Y.; Kang, H. Melatonin is a potential target for improving post-harvest preservation of fruits and vegetables. Front. Plant Sci. 2019, 10, 1388. [CrossRef]

27. Choi, G.H.; Back, K. Cyclic 3-hydroxymelatonin exhibits diurnal rhythm and cyclic 3-hydroxymelatonin overproduction increases secondry tillers in rice by upregulating MOC1 expression. Melatonin Res. 2019, 2, 120-138. [CrossRef]

28. Shah, A.A.; Ahmed, S.; Yasin, N.A. 2-Hydroxymelatonin induced nutritional orchestration in Cucumis sativus under cadmium toxicity: Modulation of non-enzymatic antioxidants and gene expression. Int. J. Phytoremediation 2009. [CrossRef]

29. Back, K.; Tan, D.X.; Reiter, R.J. Melatonin biosynthesis in plants: Multiple pathways catalyze tryptophan to melatonin in the cytoplasm or chloroplasts. J. Pineal Res. 2016, 61, 426-437. [CrossRef]

30. Ye, T.; Yin, X.; Yu, L.; Zheng, S.J.; Cai, W.J.; Wu, Y.; Feng, Y.Q. Metabolic analysis of the melatonin biosynthesis pathway using chemical labeling coupled with liquid chromatography-mass spectrometry. J. Pineal Res. 2019, 6, e12531. [CrossRef]

31. Shi, H.; Qian, Y.; Tan, D.X.; Reiter, R.J.; He, C. Melatonin induces the transcripts of CBF/DREB1s and their involvement in both abiotic and biotic stresses in Arabidopsis. J. Pineal Res. 2015, 59, 334-342. [CrossRef]

32. Byeon, Y.; Lee, H.Y.; Hwang, O.J.; Lee, H.J.; Lee, K.; Back, K. Coordinated regulation of melatonin synthesis and degradation genes in rice leaves in response to cadmium treatment. J. Pineal Res. 2015, 58, 470-478. [CrossRef]

33. Lee, K.; Choi, G.H.; Back, K. Cadmium-induced melatonin synthesis in rice requires light, hydrogen peroxide, and nitric oxide: Key regulatory roles for tryptophan decarboxylase and caffeic acid $O$-methyltransferase. J. Pineal Res. 2017, 63, e12441. [CrossRef]

34. Reiter, R.J.; Mayo, J.C.; Tan, D.X.; Sainz, R.M.; Alatorre-Jimenez, M.; Qin, L. Melatonin as an antioxidant: Under promises but over delivers. J. Pineal Res. 2016, 61, 253-278. [CrossRef]

35. Hogewoning, S.W.; Trouwborst, G.; Maljaars, H.; Poorter, H.; van Leperen, W.; Harbinson, J. Blue light dose-responses of leaf photosynthesis, morphology, and chemical composition of Cucumis sativus grown under different combinations of red and blue light. J. Exp. Bot. 2010, 61, 3107-3117. [CrossRef]

36. Kay, S.A.; Keith, B.; Shinozaki, K.; Chye, M.L.; Chua, N.H. The rice phytochrome gene: Structure, auto regulated expression, and binding of GT-1 to a conserved site in the 5' upstream region. Plant Cell 1989, 1, 351-360.

37. Jeong, D.H.; Lee, S.; Kim, S.L.; Hwang, I.D.; An, G. Regulation of brassinosteroid responses by phytochrome B in rice. Plant Cell Environ. 2007, 30, 590-599. [CrossRef]

38. Piao, W.; Kim, E.Y.; Han, S.H.; Sakuraba, Y.; Paek, N.C. Rice phytochrome B (OsPhyB) negatively regulates dark- and starvation-induced leaf senescence. Plants 2015, 4, 644-663. [CrossRef]

39. Jeon, J.S.; Lee, S.; Jung, K.H.; Jun, S.H.; Jeong, D.H.; Lee, J.; Kim, C.; Jang, S.; Yang, K.; Nam, J.; et al. T-DNA insertional mutagenesis for functional genomics in rice. Plant J. 2000, 22, 561-570. [CrossRef]

40. Zheng, X.; Tan, D.X.; Allan, A.C.; Zuo, B.; Zhao, Y.; Reiter, R.J.; Wang, L.; Wang, Z.; Guo, Y.; Zhou, J.; et al. Chloroplastic biosynthesis of melatonin and its involvement in protection of plants from salt stress. Sci. Rep. 2017, 7, 41236. [CrossRef]

41. Murch, S.J.; Krishna Raj, S.; Saxena, P.K. Tryptophan is a precursor for melatonin and serotonin biosynthesis in in vitro regenerated St. John's wort (Hypericum perforatum L. cv. Anthos) plants. Plant Cell Rep. 2000, 19, 698-704. [CrossRef]

42. Afreen, F.; Zobayed, S.M.; Kozai, T. Melatonin in Glycyrrhiza uralensis: Response of plant roots to spectral quality of light and UV-B radiation. J. Pineal Res. 2006, 41, 108-115. [CrossRef]

43. Tan, D.X.; Manchester, L.C.; Mascio, P.; Martinez, G.R.; Prado, F.M.; Reiter, R.J. Novel rhythms of N1-acetyl-N2-formyl-5-methoxykynuramine and its precursor melatonin in water hyacinth: importance for phytoremediation. FASEB J. 2007, 21, 1724-1729. [CrossRef]

44. Das, K.; Roychoudhury, A. Reactive oxygen species (ROS) and response of antioxidants as ROS-scavengers during environmental stress in plants. Front Environ Sci. 2014, 2, 53.

45. Lee, H.Y.; Back, K. Melatonin induction and its role in high light stress tolerance in Arabidopsis thaliana. J. Pineal Res. 2018, 65, e12504. [CrossRef] 
46. Byeon, Y.; Lee, H.Y.; Lee, K.; Park, S.; Back, K. Cellular localization and kinetics of the rice melatonin biosynthetic enzymes SNAT and ASMT. J. Pineal Res. 2014, 56, 107-114. [CrossRef]

47. Byeon, Y.; Back, K. Molecular cloning of melatonin 2-hydroxylase responsible for 2-hydroxymelatonin production in rice (Oryza sativa). J. Pineal Res. 2015, 58, 343-351. [CrossRef]

48. Lee, K.; Hwang, O.J.; Back, K. Rice N-acetylserotonin deacetylase regulates melatonin levels in transgenic rice. Melatonin Res. 2020, 3, 32-42. [CrossRef]

49. Ouzounis, T.; Rosenqvist, E.; Ottosen, C.O. Spectral effects of artificial light on plant physiology and secondary metabolism: A review. Hort. Science 2015, 50, 1128-1135. [CrossRef]

50. Krahmer, J.; Ganpudi, A.; Abbas, A.; Romanowski, A.; Halliday, K.J. Phytochrome, carbon sensing, metabolism, and plant growth plasticity. Plant Physiol. 2018, 176, 1039-1048. [CrossRef]

51. Roy, A.; Sahoo, D.; Tripathy, B.C. Involvement of phytochrome A in suppression of photomorphogenesis in rice seedling grown in red light. Plant Cell Environ. 2013, 36, 2120-2134. [CrossRef]

52. Lee, K.; Back, K. Melatonin-deficient rice plants show a common semidwarf phenotype either dependent or independent of brassinosteroid biosynthesis. J. Pineal Res. 2019, 66, e12537. [CrossRef]

53. Hwang, O.J.; Back, K. Melatonin deficiency confers tolerance to multiple abiotic stresses in rice via decreased brassinosteroid levels. Int. J. Mol. Sci. 2019, 20, 5173. [CrossRef]

(C) 2020 by the authors. Licensee MDPI, Basel, Switzerland. This article is an open access article distributed under the terms and conditions of the Creative Commons Attribution (CC BY) license (http://creativecommons.org/licenses/by/4.0/). 